\title{
Socio-demographic profile and maternal-fetal prognosis of emergency caesarean section versus caesarean section programmed on scar uterus
}

\author{
Mapatano Shalamba E. ${ }^{1 *}$, Mwambali Nabintu ${ }^{1}$, Nyakio Ngeleza O. ${ }^{1}$, Mukanga Omar ${ }^{2}$, \\ Mulindwa Murhula J. ${ }^{3}$, Mukwege Mukengere D. ${ }^{1}$
}

\begin{abstract}
${ }^{1}$ Department of Gynecology and Obstetrics, School of Medicine, Panzi Hospital, Evangelical University in Africa, Bukavu/DRC

${ }^{2}$ Public Health/Official University of Bukavu/DRC

${ }^{3}$ Department of Pediatric, High School of Medicine, Panzi Hospital, Evangelical University in Africa, Bukavu/DRC
\end{abstract}

Received: 14 January 2020

Revised: 23 February 2020

Accepted: 29 February 2020

\section{*Correspondence:}

Dr. Mapatano Shalamba E.,

E-mail: shalamba2mapatano@gmail.com

Copyright: (C) the author(s), publisher and licensee Medip Academy. This is an open-access article distributed under the terms of the Creative Commons Attribution Non-Commercial License, which permits unrestricted non-commercial use, distribution, and reproduction in any medium, provided the original work is properly cited.

\section{ABSTRACT}

Background: The objective of this study was to determine the maternal-fetal prognosis of emergency caesarean sections on the scar uterus to contribute to the reduction of maternal-fetal morbidity and mortality.

Methods: An analytical cross-sectional study of pregnant women who were observed from admission to discharge including their newborns at Panzi Reference General Hospital in gynecology and obstetrics department. The sample was comprehensive for convenience consisting of 150 deliveries by caesarean section who had previously delivered at least once by caesarean section. (In 4 months, from $01^{\text {st }}$ December 2018 to $31^{\text {st }}$ March 2019). A pre-established survey sheet allowed us to collect the data. For data analysis, SPSS software and Microsoft excel were used. The chi-square test was used at the 0.05 level.

Results: A total $95.2 \%$ of newborns were found to be of normal weight, their mothers were emergency cesarized but should be programmed and macrosomia was noted in 4.8\%; ( $p>0.05)$. In addition, $57.1 \%$ of urgent caesarean sections scheduled to be performed were performed in female children ( $\mathrm{p}<0.05)$. We note the low Apgar in $26.2 \%$ of newborns whose mothers were emergency cesarized but should be programmed; ( $p<0.05)$. Afterwards, $33.3 \%$ of the emergency cesarized gestates, their newborns were transferred to neonatology with transfer reasons asphyxia light in $50 \%$, moderate asphyxia in $28.5 \%$ and in $21.5 \%$ for the infectious risk. The neonatal prognosis at discharge, we noted two cases of neonatal deaths or $4.7 \%$ in pregnant emergency cesarized ( $p>0.05)$. On the maternal side, morbidity was dominated by puerperal infections in $16.7 \%$ and uterine rupture in $2.4 \%$ in the emergency caesarean section, and no maternal deaths occurred in both groups during the study period.

Conclusions: Maternal-fetal prognosis was characterized by asphyxia, neonatal infection and two cases of neonatal death. Study did not register a maternal death but we noticed puerperal infections.

Keywords: Emergency caesarean section, Maternal-fetal prognosis, Planned cesarean section

\section{INTRODUCTION}

Caesarean section is a major obstetric intervention widely recognized as an effective means of reducing maternal and perinatal mortality. ${ }^{1,2}$ Like any surgery, it can lead to maternal and neonatal complications that can increase if its use is abusive, inappropriate or not medically justified. It can compromise the prognosis of subsequent pregnancies. ${ }^{3}$ In recent decades, the frequency of caesarean section has been steadily increasing, but this 
increase differs enormously from one country to another and in the same environment, from one medical institution to another. ${ }^{4,5}$ The reasons are multifactorial: socio-economic and cultural factors, the variation of professional practices from one hospital center to another, etc. 6,7

In addition, advances in surgery, anaesthesiology and blood transfusion ensure a certain safety in performing caesarean section. ${ }^{8}$ However, since 1985, the World Health Organization (WHO) has recommended a rate of 10 to $15 \%$ as a proportion of births in the population. Outside this range, there is a global health risk and therefore no justification. ${ }^{9}$ The lack of a standardized and internationally accepted classification system for comparing caesarean section rates between countries and hospitals is also one of the factors that has contributed to the low level of awareness among service managers and health professionals to the caesarean epidemic in the world. ${ }^{10}$ Since 2014, WHO has recommended the use of Robson's classification as a global standard for the evaluation, monitoring and comparison of caesarean section rates in health facilities. ${ }^{11}$

Study receive women who go through the prayer rooms, women who believe that a caesarean section is a curse, women who complain about the socio-economic level and others who are forced by their husbands to give birth only by the children natural ways, and all these gestants are operated urgently in study center maternity. The objective of this study is to determine the maternal-fetal prognosis of emergency caesarean section to contribute to the reduction of maternal-fetal morbidity and mortality.

\section{METHODS}

It was a cross analytic sectional study purposes where pregnant women (delivery) were observed from admission to discharge including their newborns. The study was carried out at Panzi Reference General Hospital in the gynecology and obstetrics department. The sample was comprehensive for convenience consisting of 150 deliveries by caesarean section who had previously delivered at least once by caesarean section from $01^{\text {st }}$ December 2018 to $31^{\text {st }}$ March.

\section{Dependent variable}

It is the spontaneous adhesion to the LCS. Independent variables: sociodemographic parameters, obstetrical history, fetal prognosis, maternal and complications. A pre-established survey sheet allowed us to collect the data.

\section{Statistical analysis}

For data analysis, SPPS software and Microsoft excel were used. The chi-square test was used at a threshold of 0.05 .

\section{RESULTS}

With regard to the Table 1, it appears that the average age of parturients cesarized in emergency was $28.87 \pm 6.34$ years versus $28.00 \pm 7.09$ years in scheduled cesarized, ( $p$ value $=0.333$ ). Study also note that most of the $77.3 \%$ of urgently needed emergency mothers came from the ibanda health zone and $16.5 \%$ came from the Kadutu health zone, $(p<0.05)$. Study observe that $62.9 \%$ of emergency caesarean parturients had a secondary level of education and $8.2 \%$ without a level of education ( $p$ $<0.05)$.

These results also point out that the majority of $68.0 \%$ of women who had emergency caesareans were Protestant ( $p>0.05$ ). The majority of $99.0 \%$ of emergency cesarized parturients were married, with a significant association ( $\mathrm{p}$ $<0.05)$.

The results in the Table 2 show that $36.6 \%$ of caesareans were performed in normal emergencies, $35.3 \%$ were scheduled caesarean section and $28.1 \%$ were emergency caesarean but should normally be scheduled.

In light of the Table 3, study note that $85.7 \%$ of emergency cesarized did not perform the ANC1 and $83.3 \%$ the ANC2, $23.8 \%$ the ANC3 and $83.3 \%$ for the ANC4. There is a significant association between the performance of ANC and the type of CBS ( $p<0.05)$. It also appears that half or $50 \%$ of emergency-type pregnant women did not do ultrasound in the $3^{\text {rd }}$ trimester of the year. Pregnancy and delivery plan was developed in only $21.4 \%$ of cases $(\mathrm{p}<0.05)$.

In the Table 4, iterative caesareans account for $76.1 \%$, vicious presentations $16.6 \%$, macrosomial $4.7 \%$, laparotomy for uterine rupture or $2.3 \%$ in the emergency caesarean section and Iterative caesareans account for $83 \%$ in the group of scheduled caesareans.

These results show that the majority is $95.2 \%$ of newborns with a normal weight, their mothers were emergency cesarized but should be programmed and macrosomia in $4.8 \%$; the association is not significant ( $\mathrm{p}$ $>0.05$ ). In addition, we note that $57.1 \%$ of urgent caesarean sections that should be scheduled, were performed in female children, ( $\mathrm{p}<0.05)$. Regarding Apgar, study note the low Apgar in $26.2 \%$ of new-borns whose mothers were emergency cesarized but should be programmed; $(\mathrm{p}<0.05)$.

Next, we must also point out that in $33.3 \%$ of emergency cesarized, their new-borns were transferred to neonatology with $50 \%$ asphyxiation as a reason for transfer, moderate asphyxia in $28.5 \%$ and in $21.5 \%$ for the infectious risk. With regard to neonatal prognosis at discharge, we note two cases of neonatal death, i.e. $4.7 \%$ among emergency-responders $(\mathrm{p}>0.05)$. 
Table 1: Sociodemographic profile of births by type of caesarean.

\begin{tabular}{|c|c|c|c|c|}
\hline Variables & Total $(n=150)$ & Emergencies (n=97) & Scheduled $(\mathrm{n}=53)$ & p value \\
\hline Mean \pm SD & $28.56 \pm 6.60$ & $28.87 \pm 6.34$ & $28.00 \pm 7.09$ & \\
\hline \multicolumn{5}{|c|}{ Age of pregnant (years) } \\
\hline 19 & $12(8.0 \%)$ & $5(5.2 \%)$ & $7(13.2 \%)$ & \multirow{4}{*}{0.333} \\
\hline $20-29$ & $67(44.7 \%)$ & $44(45.4 \%)$ & $23(43.4 \%)$ & \\
\hline $30-39$ & $66(44.0 \%)$ & $45(46.4 \%)$ & $21(39.6 \%)$ & \\
\hline$\geq 40$ & $5(3.3 \%)$ & $3(3.1 \%)$ & $2(3.8 \%)$ & \\
\hline \multicolumn{5}{|l|}{ Address } \\
\hline Other (out of town) & $16(10.7 \%)$ & $5(5.2 \%)$ & $11(20.8 \%)$ & \multirow{4}{*}{0.022} \\
\hline Bagira & $2(1.3 \%)$ & $1(1.0 \%)$ & $1(1.9 \%)$ & \\
\hline Ibanda & $111(74.0 \%)$ & $75(77.3 \%)$ & $36(67.9 \%)$ & \\
\hline Kadutu & $21(14.0 \%)$ & $16(16.5 \%)$ & $5(9.4 \%)$ & \\
\hline \multicolumn{5}{|l|}{ Level of study } \\
\hline Illiterate & $21(14.0 \%)$ & $8(8.2 \%)$ & $13(24.5 \%)$ & \multirow{4}{*}{0.017} \\
\hline Primary & $19(12.7 \%)$ & $16(16.5 \%)$ & $3(5.7 \%)$ & \\
\hline Secondary & $90(60.0 \%)$ & $61(62.9 \%)$ & $29(54.7 \%)$ & \\
\hline University & $20(13.3 \%)$ & $12(12.4 \%)$ & $8(15.1 \%)$ & \\
\hline \multicolumn{5}{|l|}{ Profession } \\
\hline Pupil/student & $3(2.0 \%)$ & $3(3.1 \%)$ & $0(0.0 \%)$ & \multirow{4}{*}{0.445} \\
\hline Official & $14(9.3 \%)$ & $7(7.2 \%)$ & $7(13.2 \%)$ & \\
\hline Household & $117(78.0 \%)$ & $75(77.3 \%)$ & $42(79.2 \%)$ & \\
\hline Informal sector & $16(10.7 \%)$ & $12(12.4 \%)$ & $4(7.5 \%)$ & \\
\hline \multicolumn{5}{|l|}{ Religion } \\
\hline Other & $6(4.0 \%)$ & $3(3.1 \%)$ & $3(5.7 \%)$ & \multirow{4}{*}{0.328} \\
\hline Catholic & $37(24.7 \%)$ & $28(28.8 \%)$ & $9(17.0 \%)$ & \\
\hline Muslim & $1(0.7 \%)$ & $0(0.0 \%)$ & $1(1.9 \%)$ & \\
\hline Protestant & $106(70.7 \%)$ & $66(68.0 \%)$ & $40(75.5 \%)$ & \\
\hline \multicolumn{5}{|l|}{ Civil status } \\
\hline Single & $6(4.0 \%)$ & $1(1.0 \%)$ & $5(9.4 \%)$ & \multirow[b]{2}{*}{0.012} \\
\hline Married & $144(96.0 \%)$ & $96(99.0 \%)$ & $48(90.6 \%)$ & \\
\hline
\end{tabular}

Table 2: Distribution of censored pregnancy by LSC.

Variables (types of caesarean section)

Elective caesarean

Emergency caesarean (normal)

Emergency C-section that should be programmed

\begin{tabular}{|ll|} 
Effective $(\mathbf{n}=\mathbf{1 5 0})$ & $\%$ \\
\hline 53 & $35.3 \%$ \\
\hline 55 & $36.6 \%$ \\
\hline 42 & $28.1 \%$ \\
\hline
\end{tabular}

Table 3: Obstetrical history of emergency cesarized pregnant women.

\begin{tabular}{|c|c|c|c|c|}
\hline Settings & & Scheduled $(n=53)$ & Emergencies (n=42) & p value \\
\hline \multirow{2}{*}{$\mathrm{ANC1}$} & Yes & $22(58.5 \%)$ & $6(14.3 \%)$ & \multirow{2}{*}{0.000} \\
\hline & No & $31(41.5 \%)$ & $36(85.7 \%)$ & \\
\hline \multirow{2}{*}{ ANC2 } & Yes & $35(47.2 \%)$ & $7(16.7 \%)$ & \multirow{2}{*}{0.000} \\
\hline & No & $28(52.8 \%)$ & $35(83.3 \%)$ & \\
\hline \multirow{2}{*}{ ANC3 } & Yes & $29(54.7 \%)$ & $32(76.2 \%)$ & \multirow{2}{*}{0.030} \\
\hline & No & $24(45.3 \%)$ & $10(23.8 \%)$ & \\
\hline \multirow{2}{*}{ ANC4 } & Yes & $53(100 \%)$ & $7(16.7 \%)$ & \multirow{2}{*}{0.000} \\
\hline & No & $0(0.0 \%)$ & $35(83.3 \%)$ & \\
\hline \multicolumn{5}{|c|}{$3^{\text {rd }}$ trimester ultrasonography } \\
\hline Yes & & $40(75.5 \%)$ & $21(50.0 \%)$ & \multirow{2}{*}{0.010} \\
\hline No & & $13(24.5 \%)$ & $21(50.0 \%)$ & \\
\hline \multicolumn{5}{|c|}{ Completed delivery plan } \\
\hline Yes & & $53(100 \%)$ & $9(21.4 \%)$ & \multirow{2}{*}{0.000} \\
\hline No & & $0(0.0 \%)$ & $33(78.6 \%)$ & \\
\hline
\end{tabular}


Table 4: Current indications for caesareans.

\begin{tabular}{|llllll|}
\hline Scheduled & Programme $(\mathbf{n}=\mathbf{5 3})$ & $\%$ & Emergency room & $(\mathbf{n = 4 2})$ & $\%$ \\
\hline Iterative & 44 & $(83.0 \%)$ & Iterative & 32 & $(76.1 \%)$ \\
\hline Vicious presentation & 5 & $(9.4 \%)$ & Vicious presentation & 7 & $(16.6 \%)$ \\
\hline Prophylactic & 2 & $(3.7 \%)$ & Macrosomia & 2 & $(4.7 \%)$ \\
\hline Convenience & 1 & $(1.8 \%)$ & Laparotomy (RU) & 1 & $(2.3 \%)$ \\
\hline Pre-eclampsia (RCIU) & 1 & $(1.8 \%)$ & - & - & - \\
\hline
\end{tabular}

Table 5: Fetal prognosis by caesarean section.

\begin{tabular}{|c|c|c|c|}
\hline Variables & Programmed $(n=53)$ & Emergencies (n=42) & p value \\
\hline \multicolumn{4}{|l|}{ Weight of new-borns } \\
\hline Low weight & $1(1.9 \%)$ & $0(0.0 \%)$ & \multirow{3}{*}{0.967} \\
\hline Normal & $43(98.1 \%)$ & $40(95.2 \%)$ & \\
\hline Macrosomic & $0(0.0 \%)$ & $2(4.8 \%)$ & \\
\hline \multicolumn{4}{|l|}{ Sex of new-borns } \\
\hline Female & $22(41.5 \%)$ & $16(42.9 \%)$ & \multirow{2}{*}{0.884} \\
\hline Male & $31(58.5 \%)$ & $24(57.1 \%)$ & \\
\hline \multicolumn{4}{|l|}{ Apgar at birth } \\
\hline Low & $1(1.9 \%)$ & $11(26.2 \%)$ & \multirow{2}{*}{0.000} \\
\hline Normal & $52(98.1 \%)$ & $31(73.8 \%)$ & \\
\hline \multicolumn{4}{|l|}{ Transfer to neonatology } \\
\hline No & $52(98.1 \%)$ & $28(66.7 \%)$ & \multirow{2}{*}{0.000} \\
\hline Yes & $1(1.9 \%)$ & $14(33.3 \%)$ & \\
\hline \multicolumn{4}{|c|}{ Reasons for neonatology transfer $(n=15)$} \\
\hline Light asphyxia and (IUGR) & $1(100 \%)$ & $7(50.0 \%)$ & \multirow{4}{*}{0.000} \\
\hline Moderate asphyxia & $0(0.0 \%)$ & $4(28.5 \%)$ & \\
\hline Prematurity & $0(0.0 \%)$ & $0(0.0 \%)$ & \\
\hline Infectious risk & $0(0.0 \%)$ & $3(21.5 \%)$ & \\
\hline \multicolumn{4}{|l|}{ Stay in neonatology $(n=15)$} \\
\hline Within 24 hours & $1(100 \%)$ & $7(50.0 \%)$ & \multirow{2}{*}{0.349} \\
\hline More than 24 hours & $0(0.0 \%)$ & $7(50.0 \%)$ & \\
\hline \multicolumn{4}{|c|}{ Neonatal prognosis at the exit } \\
\hline Good & $53(100 \%)$ & $40(95.2 \%)$ & \multirow{2}{*}{0.110} \\
\hline Deceased & $0(0.0 \%)$ & $2(4.7 \%)$ & \\
\hline
\end{tabular}

Table 6: Maternal prognosis by caesarean section.

\begin{tabular}{|c|c|c|c|}
\hline Variables & Programmed $(n=53)$ & Emergencies (n=42) & p value \\
\hline \multicolumn{4}{|l|}{ Complications during delivery labor } \\
\hline Any & $53(100 \%)$ & $34(80.9 \%)$ & \multirow{3}{*}{0.000} \\
\hline UR & $0(0.0 \%)$ & $1(2.4 \%)$ & \\
\hline AFD & $0(0.0 \%)$ & $7(16.6 \%)$ & \\
\hline \multicolumn{4}{|c|}{ Complications during the caesarean section } \\
\hline Any & $50(94.3 \%)$ & $37(88.0 \%)$ & \multirow{5}{*}{0.278} \\
\hline Anaesthetics & $1(1.9 \%)$ & $1(2.4 \%)$ & \\
\hline Placental abnormalities & $2(3.8 \%)$ & $2(4.8 \%)$ & \\
\hline Circular cord $2 \mathrm{x}$ and shoulder strap & $0(0.0 \%)$ & $1(2.4 \%)$ & \\
\hline Hemorrhage & $0(0.0 \%)$ & $1(2.4 \%)$ & \\
\hline \multicolumn{4}{|l|}{ Postpartum complications } \\
\hline Any & $53(100 \%)$ & $35(83.3 \%)$ & \multirow{4}{*}{0.000} \\
\hline pelvic inflammatory disease & $0(0.0 \%)$ & $1(2.4 \%)$ & \\
\hline Endometritis & $0(0.0 \%)$ & $2(4.8 \%)$ & \\
\hline Parietal infection & $0(0.0 \%)$ & $4(9.5 \%)$ & \\
\hline
\end{tabular}


Regarding complications during labor, we noted that $16.6 \%$ of emergency cesarized but expected to be scheduled presented acute fetal distress (AFD) and $2.4 \%$ uterine rupture. It also appears for complications during LCS, in $4.8 \%$ study noted placental abnormalities. Study note that the complications are statistically associated with the type of caesarean section $(\mathrm{p}<0.05)$.

\section{DISCUSSION}

\section{Frequency of emergency cesarean section on scar uterus}

In this series, the emergency cesarean section rate was $44.2 \%$ and the caesarean section was $55.8 \%$. These results are different from those found in several randomized studies showing the prevalence of emergency Caesarean section compared to scheduled cesarean section. Faye D et al who found the predominance of emergency caesarean section in $70 \%$ of cases, Traoré and al, found $91.40 \%$ of cases against $8.60 \%$ of scheduled cesareans, Rowaily found $67 \%$ of urgent cases against $33 \%$ of scheduled cases. ${ }^{12-14}$ This low rate in this series excludes all caesarean sections on uterus scarred having previously benefited from a uterine test in study center maternity.

\section{Sociodemographic profile of cesareans made in emergencies}

In this study, it appears that the average age of the emergency cesarized parturients was $28.87 \pm 6.34$ years as standard deviation versus $28.00 \pm 7.09$ years in the programmed cesarized, ( $p$ value $=0.333$ ), study results are close to the other authors, Raha Maroyi. ${ }^{15}$

In 2016, Yaich $\mathrm{P}$ et al, Benzouina $\mathrm{S}$ et al, study results are explained by the fact that it is the sexually active age group in which many women prefer to have children. ${ }^{16,17}$ Regarding the level of study, study observe that $62.9 \%$ of parturient cesarized emergency, and $54.7 \%$ of cesareans programmed had a secondary level of study. These results are identical to those of Maroyi R. ${ }^{15}$ Foumane $\mathrm{P}$ et al and Mbungu MR et al, who found that the majority of cesarean deliveries had a secondary level of education. ${ }^{18,19}$ On the other hand, study results are different from those found by Benzouina $S$ et al, and Traoré et al, cited by Raha $\mathrm{M}$ in his study on multicicatricial uterus in Mali, found a predominance of out-of-school women versus those with secondary education. ${ }^{17}$

In this series, housewives were the majority in $77.3 \%$ of cases. Study results are close to those found by Mbungu MR et al and those of Alexis Y et al. ${ }^{19,20}$ Study results could be explained by the fact that the household is the main activity of women, but also by the fact that most women were out of school therefore having no professional activity to carry out.
Study also note that $99.0 \%$ of emergency parturient mothers were married and only $1 \%$ single, the gestational status is statistically related to the type of caesarean section. Study results are close to those found by Amani $\mathrm{M}$ et al, according to the author $92.7 \%$ are married. ${ }^{21}$ This result would be justified by the fact that the city of Bukavu is considered city of many marriages.

\section{Obstetric history of emergency caesarean pregnancy}

In this study, noticed $83.3 \%$ of the caesareans in emergency caesareans whose delivery should be scheduled did not make the ANC4 called the consultation of the ninth month against $100 \%$ in the group of the planned caesareans although study noted ANC intermediaries this study follow-ups in the group of scheduled cesareans, ANC3, ANC2, ANC1 performed respectively in $54.7 \%, 47.2 \%$ and $58.5 \%$. There is a significant association between the achievement of ANC and the type of LCS $(\mathrm{p}<0.05)$.

Study results agree with those of Maroy R, had found that only $18.7 \%$ of patients with uterine multi-scarring respected 4 ANCs against $81.3 \%$ who did not do ANC4 which remains a challenge to be met to improve the maternal-fetal prognosis. ${ }^{15}$ Stud results are similar to those of Baldé IS who found in his study on the evaluation of the quality of the last prenatal consultation of a peripheral maternity hospital in Conakry that the frequency of the last ANC was $28.2 \% .^{22}$ This proves that so far study ANCs have suffered from quality and it suggests that in view of these realities, the need for good follow-up of women. In this series, all women operated on in emergencies for which their cesarean section should be scheduled already presented a risk for their pregnancy and these pregnant women should follow ANC by a gynecologist-obstetrician according to the recommendations of follow-up B of HAS France. ${ }^{23}$

Samaké BM et al, had shown that women who gave less than 4 antenatal consultations were more likely to have a complication with $\mathrm{OR}=1.87 \quad(1.10-3.17)$ hence the importance of good follow-up of Numerous and high quality ANCs to reduce the risks during childbirth and in the postpartum period. ${ }^{24}$ Quality prenatal consultation is one of the three pillars of the fight against maternal and neonatal morbidity and mortality, and its importance is well established. ${ }^{25}$ They were thus the main lever modified in the WHO recommendations of November 2016, with now eight minimum visits recommended, within the framework of the last development objectives (ODDs). ${ }^{26}$

Traoré et al, as Aboubakari et al, feel that not performing the ANC has contributed to the increased rate of emergency caesarean section in their studies and the poor maternal-fetal prognosis. ${ }^{27,28}$ In this study, the delivery plan was developed in only $21.4 \%$ of cases $(p<0.05)$ and in $78.6 \%$ the delivery plan was not developed, which proves that the quality of ANC in this environment 
remains to be improved, but improving maternal and fetal prognosis requires quality prenatal consultations to screen for pregnancies at risk of HAS. ${ }^{23}$

Study results differ from those found in the literature, Ole SB et al, reported that among pregnant women followed in prenatal consultations, the route of delivery was not indicated in $33.73 \%$ of women who were parturient. ${ }^{29}$ I.S. Balde made the same constant on prenatal consultations: the prognosis for childbirth was never asked or mentioned in ANC in the health book. As a result, some pregnant women, who could have benefited either from a prophylactic cesarean or from a labor trial, were evacuated in disaster for an obstetric rescue intervention, often after prolonged and laborious work in peripheral maternities or birthing homes. ${ }^{22}$ Alongside routine ANC, an updated approach to prenatal care called refocused ANC or focused ANC, which is defined as the total medical care a woman receives during pregnancy, helping to ensure that she and her newborn survive healthy pregnancy and childbirth. ${ }^{30}$ It emphasizes the quality of the ANCs rather than their number.

Regarding the current indications for current cesareans, the indications were dominated by iterative cesareans in $83 \%$ and $76.1 \%$ respectively in the group of scheduled and emergency cesareans. These results are different from those found by Cisse CT et al, who found 30-40\% of iterative indications, study results are explained by the high number of multi-registry uterus although the pelvis was normal but also the bicicatricial uteri at unfavorable obstetric conditions. ${ }^{31}$

The compulsory indications found on scar uterus are the same as for these authors: a foeto-pelvic disproportion, a dystocic presentation, a multicicatricric uterus, a body scar, a history of uterine rupture, an associated pathological condition at high maternal and/or fetal risk. ${ }^{32-34}$ Study department receives a large number of women with previous cesarean sections done elsewhere with as pejorative elements: lack of information on the previous indications, the type and quality of the uterine scar, all these elements lead us to iterative cesareans after sometimes two caesareans.

Neonatal morbidity and mortality according to types of cesarean section the results of this study show that the majority of newborns in the two groups had a normal weight $(95.2 \%$ in the group of emergency caesareans and $98.1 \%$ in the group of scheduled caesareans, the association was not not significant. Study results are similar to those of other authors. ${ }^{17,35}$

Study noted 2 cases of fetal macrosomia in the group of emergency caesareans, A review of the literature on the attempt of labor delivery in a scar uterus proves an increase in the rate of ruptures in women with scar uterus and without a history of vaginal delivery with newborns whose weight was greater than or equal to $4000 \mathrm{~g} .{ }^{36}$ The male sex was predominant in this study for the two groups of scheduled and urgent cesareans of $58.5 \%$ and $57.1 \%$ respectively, Benzouina $\mathrm{S}$ and Beena $\mathrm{D}$ et al, found no difference for the two sexes in their studies. ${ }^{17,37}$ Study results are close because the difference was not statistically significant. For the Apgar score, the poor Apgar score was associated with emergency caesareans in $26.2 \%$ of cases compared to $1.9 \%$ of cases in the group of scheduled cesareans, the difference was statistically significant; $(p<0.05)$. Study results are close to those of Soukayna B et al who found in both groups the fetal morbidity was $28.2 \%$, and of this percentage $90.36 \%$ concern the group of cesarean sections performed in emergency versus $9.64 \%$ in the groups of scheduled cesareans or electives, morbidity mainly linked to perinatal asphyxia, Elvedi-Gasparovic, had also found that in the group of scheduled cesareans, the newborn had a considerably better Apgar score than in the group of emergency caesareans. ${ }^{17,38}$ Sima Ole B et al reported the same results: Apgar was $8.33 \pm 1.8(7-10)$ when the cesarean was scheduled and $5.33 \pm 0.5(0-7)$ when it was done during work. ${ }^{29}$

However, study results differ from those found by other authors in their studies such as: Subedi A et al, found $100 \%$ of good score of Apgar in the group of scheduled caesareans and $98.3 \%$ in the group of emergency caesareans, for this author the difference was not statistically significant. ${ }^{39}$ In the study by Schindu P et al, $11.4 \%$ of emergencies and $9.8 \%$ of cases in the group of scheduled cesareans had a poor perinatal prognosis, but this finding was not statistically significant. ${ }^{40}$

The explanations in this study would be linked to this increase in caesarean sections performed in emergencies, because pregnant women preferred to start labor at home or in a low level structure to attempt vaginal delivery without any fetal monitoring or surveillance poor and this could explain this poor Apgar score of newborns whose mothers belonged to the group of emergency caesareans. Regarding the transfer of newborns to the neonatal unit, we must also note that $33.3 \%$ of newborns were transferred to neonatology with the main reason for transfer being mild asphyxiation in 50\%, asphyxiation moderate in $28.5 \%$ and in $21.5 \%$ for the risk of infection in the group of emergency caesareans, compared to the group of scheduled cesareans where only one newborn was transferred to neonatology for mild asphyxia and IUGR, the difference was statistically significant. In addition, it should be noted that the stay in neonatology was more than 24 hours in half of the cases, i.e. $50 \%$.

Ugwe E et al, reports similar results for emergency caesareans, 27\% mild asphyxia, 21\% moderate asphyxia and $11.9 \%$ severe asphyxia, however study results are different in the group of scheduled cesareans in which we noted 1 case of mild asphyxiation with intra uterine growth retardation (IUGR). ${ }^{41}$ Ayano B et al, had found in their study that $18.6 \%$ of newborns admitted to the neonatal service in the group of caesarean sections performed in emergency. ${ }^{42}$ With regard to the neonatal 
prognosis at discharge, study noted two cases of neonatal death, i.e. $4.7 \%$ in pregnant cesareans in emergency and no case of death in the group of scheduled cesareans ( $p$ $>0.05$ ). Study results are similar to those of Ugwe E, who found $3.9 \%$ perinatal death in the group of emergency caesareans and no case of perinatal death for scheduled cesareans. ${ }^{41}$ Study results differ from those reported by London $\mathrm{MB}$ et al who found respectively $0.08 \%$ in the group of emergency cesareans and $0.05 \%$ in the group of scheduled cesareans with a $\mathrm{p}=0.19 .{ }^{35}$ Perinatal mortality is the most feared event. The attempted vaginal way leads to neonatal excess mortality with a rate of 110 to 129 against 11 to 60 deaths per 100,000 births for scheduled iterative cesareans, an OR of $11.6(\mathrm{p}=0.02) .{ }^{43}$

\section{Maternal morbidity and mortality of caesarean sections performed in emergency or complications}

In this series, we noted that maternal morbidity was dominated by puerperal infections and uterine rupture in $16.7 \%$ and $2.4 \%$ respectively. Cyr Espérance in his study, he had found that maternal morbidity was more linked to the frequency of dehiscence's of the uterine scar was $1 \%$ and that of uterine rupture was $0.8 \% .{ }^{44}$ It also emerges with regard to complications during cesarean section, in $4.8 \%$ we noted placental anomalies, a case of hemorrhage, a case of procidence of the cord. We noted that the complications are statistically associated with the type of cesarean section. Scheller A et al in his study: comparison of the rate of complications after primary, secondary and emergency cesarean section in 1992, reports a significant proportion of complications in the group of caesarean sections performed in emergency, complications dominated by significant blood loss. ${ }^{45}$

In this series study found that complications in the postpartum period were significant in the group of caesarean sections performed in emergencies dominated by parietal infections, endometritis and pelvi peritonitis, compared to scheduled cesarean sections, the difference was statistically significant $(\mathrm{p}<0.05)$. Other authors have found results similar to ours: postoperative morbidity was more pronounced in patients who had an emergency cesarean than in those who had a scheduled cesarean. The difference was statistically significant $(\mathrm{p}<0.001)$, Ugwe $\mathrm{E}$ et al, in his work reported $7.6 \%$ of parietal infection in the group of caesareans made in emergencies against $1.4 \%$ for scheduled cesareans, Kathryn E et al. ${ }^{39,41,46}$ In 2019 also found in his study that the risk of having a puerperal infection was significant during cesarean after attempting the vaginal route than in scheduled cesarean, London MB et al. ${ }^{35}$ In 2004 reported that the complication that dominated the postpartum period was endometritis in the group of caesarean sections performed in an emergency after attempted vaginal delivery. In this work, we did not record maternal deaths in the two groups during the study period, we justify this by the immediate and adequate management by cesarean section of those parturients who came in emergency when their cesarean section should be scheduled. And thus, prevent the dramatic complications of maternal mortality. EOV Ugwe et al, reported different but close results from this study, $0.1 \%$ and $0.6 \%$ of maternal death respectively in the group of scheduled caesareans and emergency caesareans. $^{41}$ Dembélé A et al, also did not report maternal death in their work, which is consistent with this study results. ${ }^{47,48}$

\section{CONCLUSION}

At the end of this study, study note that the maternal-fetal prognosis was good in the group of scheduled caesarean sections compared to emergency caesarean sections where the fetal prognosis was marked by cases of death from suffocation, and the maternal prognosis dominated by surgical site infections and puerperal infections.

\section{Funding: No funding sources Conflict of interest: None declared \\ Ethical approval: The study was approved by the Institutional Ethics Committee}

\section{REFERENCES}

1. Dujardin B, Mine F, De Brouwere V. Improving maternal health: a guide for systemic action. The Harmattan. 2014:310.

2. Kim YM, Tappis H, Zainullah P, Ansari N, Evans C, Bartlett L, et al. Quality of caesarean delivery services and documentation in first-line referral facilities in Afghanistan: a chart review. BMC Preg Childbirth. 2012;12:14.

3. Kaboré C, Ridde V, Kouanda S, Agier I, Queuille L, Dumont A. Determinants of non-medically Indicated cesarean deliveries in Burkina Faso. Int J Gynaecol Obstet. 2016;135 Suppl 1:S58-S63.

4. Betrán AP, Ye J, Moller AB, Zhang J, Gülmezoglu $\mathrm{AM}$, Torloni MR. The increasing trend in caesarean section rates: Global, Regional and National Estimates: 1990-2014. PLoS One. 2016;11(2):e0148343.

5. Vogel JP, Betran AP, Vindevoghel N, Souza JP, Torloni MR, Zhang J, et al. Use of the Robson classification to assess caesarean section trends in 21 countries: a secondary analysis of two WHO multicountry surveys. Lancet Glob Health. 2015;3(5):e260-70.

6. Dhodapkar SB, Bhairavi S, Daniel M, Chauhan NS, Chauhan RC. Analysis of caesarean sections according to Robson's ten group classification system at a tertiary care teaching hospital in South India. Int J Reprod Contracept Obstet Gynecol. 2015;4:745-9.

7. Mi J, Liu F. Rate of caesarean section is alarming in China. Lancet. 2014;383(9927):1463-4.

8. Elshani B, Daci A, Gashi S, Lulaj S. The incidence of caesarean sections in the university clinical center of Kosovo. Acta Inform Med. 2012;20(4):244-8.

9. de la Santé OM. Déclaration de l'OMS sur les taux de césarienne. Genève. OMS. 2014. 
10. Betran AP, Vindevoghel N, Souza JP, Guelmezoglu AM, Torloni MR. A systematic review of the Robson classification for caesarean section: what works, doesn't work and how to improve it. PloS One. 2014;9(6):e97769.

11. Betran AP, Torloni MR, Zhang JJ, Gülmezoglu AM, WHO working group on caesarean section. WHO statement on caesarean section rates. BJOG Int $\mathrm{J}$ Obstet Gynaecol. 2016;123(5):667-70.

12. Faye DM, Moreira P, Tamofo E, Diouf AA, Moreau JC. Monitoring of pregnancies on scar uterus: Qualitative aspects and prognostic implications. Artic Orig Health Medicine. Artic Orig Health Medicine Too. 2014;24:409-15.

13. Traoré B, Kokaina C, Beye SA, Traoré M, Dolo A. Cesarean section at the Ségou regional hospital center in Mali. Med Afr Noire. 2010;57(11):513-8.

14. Al Rowaily MA, Alsalem FA, Abolfotouh MA. Cesarean section in a high-parity community in Saudi Arabia: clinical indications and obstrics outcomes. BMC Preg Childbirth. 22014;2014:14-92.

15. Maroyi R. Déterminanats de la morbidité maernoinfantile sur utérus multicicatriciel dans 5 hopitaux au Sud-Kivu. Pub Votre Trava. 2017.

16. Yaïch P, Ouattara A, Koffi N. Caesareans in emergency: maternal-fetal prognosis at CHU Cocody Abidjan. Af J Anesthesia Emerg Med. 2012;2012.

17. Benzouina S, Boubkraoui ME, Mrabet M, Chahid N, Kharbach A, Elhassani A, Barkat A. Fetal outcome in emergency versus elective cesarean sections at Souissi Maternity Hospital, Rabat, Morocco. Pan African Medical Journal. 2016;23(1):1-10.

18. Foumane P, Koh VM, Minkande JZ, Ngantcha EN, Dohbit JS, Mboudou ÉT. Risk factors and prognosis of emergency cesarean delivery at the Yaounde Women's and Children's Hospital, Cameroon. Medecine et Sante Tropicales. 2014;24(1):89-93.

19. Mbungu MR, Ntela MJ, Kahindo MP. Frequency of CLRs according to the ROBSON classification in 3 maternity wards in the city of KINSHASA in the DRC. 2017;10(2):2535-44.

20. Sawadogo YA, Komboigo E, Kiemtore S, Zamane H, Ouedraogo I, Kain DP, et al. Post cesarean parietal suppurations at the Center Hospitalier Universitaire Yalgado Ouedraogo, Burkina-Faso: epidemiological, clinical, therapeutic and prognostic aspects. Pan African Med J. 2019:32.

21. Maleya A, Kakudji YK, Mwazaz RM, Nsambi JB, Ngwej HI, Mukuku O, et al. Maternal-fetal outcomes of untreated pregnancies in Lubumbashi, Democratic Republic du Congo. Pan African Med J. 2019;33.

22. Baldé IS, Diallo FB, Diallo MH, Sylla I, Bah EM, Mamy MN, et al. Quality assessment of the last prenatal consultation in a peripheral maternity hospital in Conakry, Guinea. J Peri Med. 2016;8(1):39-45.

23. Suivi B. Monitoring and orientation of pregnant women according to identified risk situations. La Revue Sage-Femme. 2007;6(4):216-8.
24. Samake BM et All. Factors of morbidity and mortality of caesarean section at the Gabrielle touré university hospital in BAMAKO. Mali Méd. 2017;32:2.

25. De Brouwere V, Van Lerberghe W. Reducing the risks of maternity: Strategies and scientific evidence. Studies in HSO, 2001. Available at: http://dspace.itg.be/bitstream/handle/10390/1514/shs op18.pdf?sequence $=1$. Accessed on $10^{\text {th }}$ December 2019.

26. World Health Organization. Standards for improving the quality of maternal and newborn care in health facilities. OMS 2017. Available at: https://apps.who.int/iris/bitstream/handle/10665/254 $673 / 9789242511215$-fre.pdf. Accessed on $10^{\text {th }}$ December 2019.

27. Traoré Y, Teguete I, Dolo A, Dicko F, Diallo A. Childbirth in a context of scar uterus at the CHU Gabriel Touré from January 2007 to December 2008: methods and complications. Black Af Med. 2012;59(11):511-6.

28. Aboubakari AS, Azoumah D, Agbetra N, Adama H, Akpadza K. Methods and complications of childbirth after cesarean section at CHU Kara. Med Afr Noire. 2009;56(3):4-8.

29. Sima Ole B, Bang Ntamack J, Obame R, Bibang F, Mewie Lendzinga A, Nzogue Nguema JP, et al. Cicatricial uterus: Epidemiological aspects and method of childbirth at the maternity hospital of UWENDO CHU in GABON. 2017:29.

30. B Kinzie, Gomez P. Basic maternal and new born care: A guide for skilled providers 2014. Avalable at: https://www.healthynewbornnetwork.org/resource/ba sic-maternal-and-newborn-care-a-guide-for-skilledproviders/Accessed 23 December 2017.

31. Cissé CT, Ewagnignon E, Terolbe I, Diadhiou F. Childbirth on scar uterus at the Dakar CHU. J Obstet Gynecol Reprod Biol. 1999;28(6):556-62.

32. Flamm BL, Newman LA, Thomas SJ, Fallon D, Yoshida MM. Vaginal birth after cesarean delivery: result of a 5 year multi-center collaborative study. Obstet Gynecol. 1990;76:750-4.

33. Benzineb N, Bellasfar M, Bouguerra B, Amri MT, Sfar R. Childbirth by vaginal route after cesarean. Rev Fr Gynécol Obstét. 1998;93:282-4.

34. De Saint Hilaire P, Gaucherand P, Bagou G, Rudigoz RC. Pregnancy and scar uterus. Encycl Medicines Chir Paris, Obstetrics. 1992;16:5-030-20.

35. Landon MB, Hauth JC, Leveno KJ, Spong CY, Leindecker S, Varner MW, et al. Maternal and perinatal outcomes associated with a trial of labor after prior cesarean delivery. New Eng J Med. 2004;351(25):2581-9.

36. Vercoustre L, Roman H. Trial of work in case of anterior caesarean: review of the literature. J Obstet Gynecol Reprod Biol. 2006;35(1):35-45.

37. Kamath BD, Todd JK, Glazner JE, Lezotte D, Lynch AM. Neonatal outcomes after elective cesarean delivery. Obstet Gynecol. 2009;113(6):1231. 
38. Elveđi-Gašparović V, Klepac-Pulanić T, Peter B. Maternal and fetal outcome in elective versus emergency caesarean section in a developing country. Coll Antropol. 2006;30(1):113-8.

39. Subedi A, Shrestha J, Adhikari KM, Shrestha A, Gurung S. Comparison of maternal and perinatal outcome in elective and emergency cesarean section in a tertiary care centre. Birat $\mathrm{J}$ Health Sci. 2019;4(1):616-20.

40. Sichundu P, Siziya S, Kumoyo M. Rate, indica ons and fetal outcome of emergency caesarean sec on-a retrospec ve study at ndola Teaching Hospital, Ndola, Zambia. Asian Pacific J Health Sci. 2017;4(2):162-7.

41. Ugwu EO, Obioha KC, Okezie OA, Ugwu AO. A five-year survey of caesarean delivery at a Nigerian tertiary hospital. Anna Med Health Sci Res. 2011;1(1):77-84.

42. Ayano B, Guto A. Indications and outcomes of emergency caesarean section at St Paul's Hospital Medical college, Addis Ababa, Ethiopia 2017:(afoul month retrospective cohort study). Gynecol Reprod Health. 2018;2(5):1-2.

43. Boneau C, Nizard J. Bonneau C, Nizard J. Management of pregnancies with a scar uterus: state of knowledge. J Gynécol Obstét Biol Reprod 2012;41(6):497-511.

44. Koulimaya-Gombet CE, Diouf AA, Diallo M, Dia A, Sène C, Moreau JC, Diouf A. Pregnancy and childbirth of patients with a history of cesarean section in Dakar: epidemiological clinical therapeutic and prognostic aspects. Pan Af Med J. 2017;27:1.

45. Scheller A, Terinde R. Comparison of the rate of complications after primary, secondary and emergency Cesarean section. J Obstet Perinatol. 1992;196(6):253-60.

46. Fitzpatrick KE, Kurinczuk JJ, Bhattacharya S, Quigley MA. Planned mode of delivery after previous cesarean section and short-term maternal and perinatal outcomes: A population-based record linkage cohort study in Scotland. PLoS Med. 2019;16(9):e1002913.

47. Koh VM, Essome H, Sama JD, Foumane P. Childbirth on scar uterus in resource-poor countries: care and becoming a mother-foetal. Pan African Med J. 2018;30:1.

48. Dembélé A, Tarnagda Z, Ouédraogo JL, Thiombiano $\mathrm{O}$, Bambara M. Result of deliveries on scar uterus in a university hospital in Burkina. Pan African Med J. 2012;12:95-102.

Cite this article as: Shalamba ME, Nabintu M, Ngeleza NO, Omar M, Murhula MJ, Mukengere MD. Socio-demographic profile and maternal-fetal prognosis of emergency caesarean section versus caesarean section programmed on scar uterus. Int $\mathrm{J}$ Reprod Contracept Obstet Gynecol 2020;9:1864-72. 